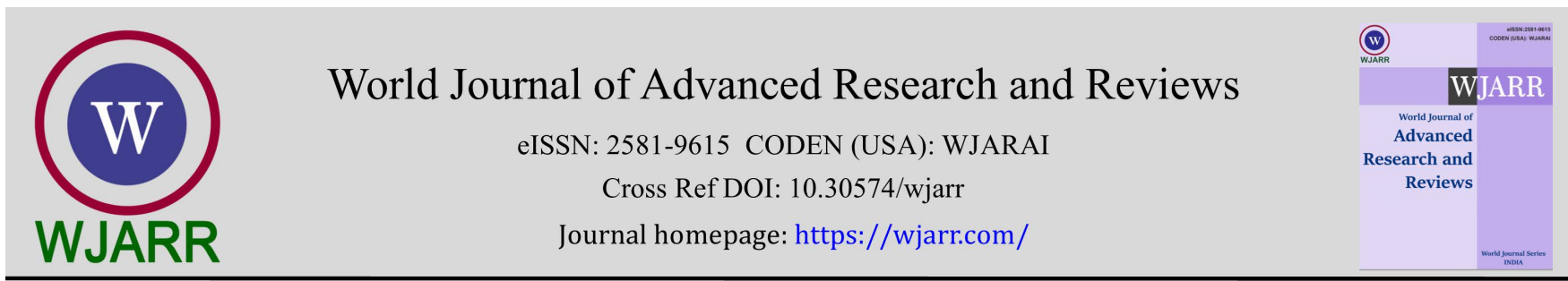

(RESEARCH ARTiClE)

Check for updates

\title{
An investigation of parental perspective of Asnani School Oral Health Program in Qatar
}

\author{
Najat Abdrabbo Alyafei ${ }^{1,}{ }^{*}$ and Bushra Naaz Fathima Jaleel 2 \\ ${ }^{1}$ Head of Public Oral Health Services, Primary Health Care Corporation, Doha, Qatar. \\ ${ }^{2}$ Coordinator of Public Oral Health Services, Primary Health Care Corporation, Doha, Qatar.
}

World Journal of Advanced Research and Reviews, 2021, 10(01), 087-093

Publication history: Received on 24 February 2021; revised on 29 March 2021; accepted on 01 April 2021

Article DOI: https://doi.org/10.30574/wjarr.2021.10.1.0133

\begin{abstract}
Oral disorders affect school children globally. Acceptability of the School Oral Health Program by parents is a vital domain that can positively impact its sustainability. This study investigates the parental perspective of the Asnani School Oral Health Program. An online questionnaire survey was conducted from April to May 2019 among 418 parents of children in public schools.

$32 \%$ of the parents rated the Asnani SOHP as excellent, $31 \%$ rated it very good, $23 \%$ rated it good, $10 \%$ rated it as average, and only $4 \%$ as poor. Three hundred forty-two children notified their parents about receiving oral health education lectures. $85 \%$ of parents reported that they had noticed a change in the child's behavior towards maintaining their oral hygiene after participating in the Asnani School Oral Health Program. The parental perspectives towards Asnani School Oral Health Program expressed in this study are very encouraging and indicate a high acceptance for the program and noticeable effective improvement in their child's oral hygiene behavior.
\end{abstract}

Keywords: School Oral Health Program; Parents; Perceptions; School Children; Qatar; Oral Health; School Program

\section{Introduction}

Poor dental health has a profound impact on people's overall health and quality in people cutting across ages. Although tooth decay is largely preventable, it remains undoubtedly the most common chronic disease and a severe public health concern amongst children in many countries across the world [1-3]. Global Burden of Disease Study estimates that more than 530 million children suffer from dental caries of primary teeth [4]. Among school-aged children, dental diseases impact not only the child's ability to eat, speak and sleep, but the pain, infection, and facial swelling associated with dental diseases significantly affect their socialization, academic performance, and school attendance [5-7]. The consequences of oral diseases among children inevitably have repercussions on the entire household, as parents may have to compromise their daily work routine to take children to the dental clinic and have to bear the high cost of dental treatment thereof [8].

Children of today go on to become adults in the future and contribute towards shaping the world. Schools provide the ideal platform for reaching out to a large number of children. Based on the Ottawa Charter for Health Promotion recommendations, oral health services, a component of the school health services, can screen, prevent, control and monitor oral diseases and conditions, and ensure maintenance of good oral health among school children [9].

Worldwide many models of School Oral Health Programs have been implemented at International, National, Regional and Local levels with numerous interventions including dental screening, oral health education (activities with lectures,

\footnotetext{
${ }^{*}$ Corresponding author: Najat Abdrabbo Alyafei

Oral Public Health, Primary Health Care Corporation, Doha, Qatar.
}

Copyright (C) 2021 Author(s) retain the copyright of this article. This article is published under the terms of the Creative Commons Attribution Liscense 4.0. 
albums, slides, leaflets, counseling, games, drawings, theatre, dietary guidance), oral hygiene instructions, supervised tooth brushing, fluoride varnish, fluoride mouthwash, fluoride gels and pit, and fissure sealants [10-13].

Any Oral Health Promotion program needs to be evaluated in appropriate timescales to ascertain its value and impact $[14,15]$. Delineating parents' perceptions about School Oral Health Programs is crucial for the program's success and sustainability. However, very few studies have evaluated the School Oral Health Programs from the parent's perspective.

In Qatar, the second decade of the 21st century witnessed heightened interest in exploring its oral health problems. National Oral Health Survey [16] and numerous other research studies have drawn attention to the high prevalence of dental caries, i.e., $73-85 \%$ among school children $[17,18]$ poor oral health behavior [19] and their low oral health knowledge [20] .

School Oral Health Clinics were established at Primary Health Centers to provide oral health care based explicitly on school children's needs. These clinics were collaborated with the Ministry of Education and Higher Education (MEHE) with the vision to aid in lowering the dental caries occurrence among primary school students. The need for preventionoriented School Oral Health Programs at school settings, utilizing mobile dental clinics, was realized as an essential component for establishing a foundation of good oral health, prevention, and oral health promotion early in children's lives.

In November 2018, an ambitious School Oral Health Program (SOHP) called "Asnani", denoting "My Teeth," was conceptualized as a universal dental coverage program for all Public Kindergarten and Primary school children, delivering comprehensive oral health services covering dental screening, prevention, oral health education, promotion, and referral services. Preventive treatments like fluoride varnish and pit and fissure sealant application have already been established as effective means in reducing the risk of developing new carious teeth $[21,22]$. The current program was created to provide onsite dental services for screening and preventive treatment by a dedicated team of Dentists and Dental Hygienists utilizing Mobile Dental Units at schools.

Being the first of its kind, this Universal Public-School Oral Health Program in Qatar needs to be evaluated for its effectiveness, feasibility, and acceptability. In this regard, establishing the acceptability of the program by parents is a vital domain that can positively impact the program, ensuring its sustainability. The objective of this study was to investigate the parental perspective of the Asnani School Oral Health Program.

\section{Methods}

This cross-sectional questionnaire survey was carried out to obtain data about Asnani School Oral Health Program's parental perspectives.

The survey was carried out from April to May 2019 as part of process evaluation for Asnani School Oral Health Program, Project Code: P0268/00, approved by Primary Health Care Corporation, Doha, Qatar. This study was conducted in compliance with the World Medical Association Declaration of Helsinki. Necessary permissions were acquired from the Principals of the schools and parents of the children.

This study was conducted in April 2019, five months after the initiation of the program. By the end of March 2019, Asnani School Oral Health Program had reached out to 12,681 children from 31 schools. Since the School Oral Health Program was in the initial phase of its implementation, and being the first of its kind in Qatar, we intended to obtain responses from all the parents. Hence, no sampling was employed, and the questionnaire was sent to all the parents of children in the schools where the Asnani School Oral Health Program was conducted till the end of March 2019. The link to the survey questionnaire was disseminated to the parents by the participating schools' school nurses through Short Message Service (SMS).

All the parents had access to the consent statement and were requested to click on the agree button to participate in the survey. The informed electronic consent included the study's object, the responsible researchers, and their contact information. Electronic informed consent from the parents to publish their anonymized information was obtained. The approximate time for completing the survey was informed as being about five minutes. To ensure the anonymity of each respondent, no identifying information was collected. The questionnaire was anonymized to obtain honest feedback. Before sending the questionnaire, parents could change their answers as many times as they wish. Parents' participation was voluntary, and full confidentiality of the collected data was ensured to the parents. The data obtained were stored in a password-protected file on the researchers' computer system and used only for this study. 
The questionnaire included ten close-ended, multiple-choice questions investigating parents' views on various components of the Asnani SOHP, which included their overall level of satisfaction, experience, and impact of the program on their child's oral hygiene behavior. The questionnaire was developed in Arabic as it is Qatar's official language and medium of instruction in Public schools. Experts in Dentistry Department at PHCC determined content validity and face validity of questionnaire.

Before distributing the questionnaire, it was checked by a pretest on ten parents from one school to assess the clarity and appropriateness. Reliability analysis was conducted using Test-Retest, and a correlation coefficient of 0.7 was obtained. Descriptive analysis of data obtained is presented in the results as frequency distributions in numbers and percentages.

\section{Results}

Of the 418 parents who responded to the survey, 86\% (359) of parents reported that their child had participated in the Asnani SOHP. When the responses of the parents whose children had participated in the survey were analyzed, it was found that overall, $32 \%$ of parents rated the Asnani SOHP as excellent, $31 \%$ very good and $23 \%$ as good, $10 \%$ rated it as average, and only $4 \%$ as poor (Table 1 ).

Table 1 Parental perspectives of Asnani School Oral Health Program

\begin{tabular}{|c|c|c|c|}
\hline & Item & Number & Percentage \\
\hline 1. & $\begin{array}{l}\text { Has your child participated in Asnani School Oral Health Program? } \\
\text { a. Yes } \\
\text { b. No }\end{array}$ & $\begin{array}{l}359 \\
59\end{array}$ & $\begin{array}{l}86 \\
14\end{array}$ \\
\hline 2. & $\begin{array}{l}\text { How do you rate the Asnani School Oral Health Program? } \\
\text { a. Excellent } \\
\text { b. Very Good } \\
\text { c. Good } \\
\text { d. Acceptable } \\
\text { e. Not good }\end{array}$ & $\begin{array}{l}115 \\
111 \\
83 \\
36 \\
14\end{array}$ & $\begin{array}{l}32 \\
31 \\
23 \\
10 \\
4\end{array}$ \\
\hline 3. & $\begin{array}{l}\text { Did your child tell you that his/her teeth were examined at school? } \\
\text { a. Yes } \\
\text { b. No }\end{array}$ & $\begin{array}{l}350 \\
9\end{array}$ & $\begin{array}{l}97.5 \\
2.5\end{array}$ \\
\hline 4. & $\begin{array}{l}\text { Did you child tell you about oral health education lectures delivered by the } \\
\text { dental professionals, demonstration of tooth brushing instructions and practice } \\
\text { sessions on mouth models using toothbrush? } \\
\text { a. Yes } \\
\text { b. No }\end{array}$ & $\begin{array}{l}342 \\
17\end{array}$ & $\begin{array}{l}95.3 \\
4.7\end{array}$ \\
\hline 5. & $\begin{array}{l}\text { Have you noticed change in the child's attitude towards oral hygiene } \\
\text { maintenance after participating in the SOHP? } \\
\text { a. Definitely Yes } \\
\text { b. To some extent } \\
\text { c. No }\end{array}$ & $\begin{array}{l}169 \\
136 \\
54\end{array}$ & $\begin{array}{l}47 \\
38 \\
15\end{array}$ \\
\hline 6. & $\begin{array}{l}\text { Did the child bring home "Parent Information Sheet"? } \\
\text { a. Yes } \\
\text { b. No }\end{array}$ & $\begin{array}{l}215 \\
144\end{array}$ & $\begin{array}{l}60 \\
40\end{array}$ \\
\hline 7. & $\begin{array}{l}\text { Would you take your child for dental treatment if it has been advised in "Parent } \\
\text { Information Sheet"? } \\
\text { a. Yes } \\
\text { b. No }\end{array}$ & $\begin{array}{l}299 \\
60\end{array}$ & $\begin{array}{l}83 \\
17\end{array}$ \\
\hline
\end{tabular}




\begin{tabular}{|c|c|c|c|}
\hline 8. & $\begin{array}{l}\text { Where would you prefer to take the child for dental treatment? } \\
\text { a. Dental clinic at Primary Health Centre } \\
\text { b. Private dental clinic }\end{array}$ & $\begin{array}{l}251 \\
108\end{array}$ & $\begin{array}{l}70 \\
30\end{array}$ \\
\hline 9. & $\begin{array}{l}\text { What do you think is the right age for the child to have his/her first visit to } \\
\text { dentist? } \\
\text { a. During kindergarten } \\
\text { b. During primary school } \\
\text { c. After primary school } \\
\text { d. Only when needed }\end{array}$ & $\begin{array}{l}226 \\
83 \\
7 \\
43\end{array}$ & $\begin{array}{l}63 \\
23 \\
2 \\
12\end{array}$ \\
\hline 10. & $\begin{array}{l}\text { Is it necessity to check child's teeth regularly? } \\
\text { a. Yes } \\
\text { b. No }\end{array}$ & $\begin{array}{l}352 \\
7\end{array}$ & $\begin{array}{l}98 \\
2\end{array}$ \\
\hline
\end{tabular}

Among the children who participated in the program, 97.5\% (350 children) informed their parents about examining their teeth at school. 95.3\% (342 children) also notified their parents about the oral health education lectures delivered by the dental professionals and demonstrated tooth brushing instructions and practice sessions on mouth models using a toothbrush. Only a small percentage of children had missed the oral examination $(2.5 \%)$ and oral health education lectures (4.7\%).

When the parents were enquired if they had noticed a change in the child's behavior towards maintaining their oral hygiene after participating in the Asnani SOHP, the majority of the parents (85\%) reported in the affirmative, i.e., $47 \%$ indicated "Definitely Yes," and 38\% indicated "To some extent."

$60 \%$ of the parents reported that the child brought home a "Parent Information Sheet" after the oral examination at school, informing the parents about the child's oral assessment, preventive treatment undertaken at school, and further referral for dental treatments. 83\% of parents were motivated to pursue dental treatment for their child following the dental professional's advice in the "Parent Information Sheet." The preferred place for dental treatment by the majority of the parents (70\%) was a dental clinic at Primary Health Centers, although $30 \%$ of parents preferred private dental clinics.

To assess the parents' knowledge towards their child's oral health, we included a question to inquire, according to them, what was the right age for the child to have his/her first visit to the dentist. $63 \%$ of parents reported it should be during kindergarten age, 23\% indicated during primary school and 2\% after primary school. Surprisingly, $12 \%$ reported only when necessary.

Parents' attitude towards their child's oral health was assessed by inquiring - "Is it necessary to check the child's teeth regularly?" Survey results provide mounting evidence that $98 \%$ of parents recognize the importance of regularly checking the child's teeth.

\section{Discussion}

The current study is the first study in Qatar and probably in the entire Middle Eastern region to examine a School Oral Health Program's parental perception. It assessed parental satisfaction, experience, and impact of the program on their child's oral hygiene behavior.

As stated by WHO in 1998, "the extent to which each nation's schools become Health-Promoting Schools will play a significant role in determining whether their next generations are educated and healthy" [9]. One of the earliest mentions in dental inspection literature among children in state-maintained schools as a statutory requirement has been reported in the United Kingdom since 1918 [24]. SOHP that offers dental screening services provides valuable data for monitoring the burden of oral diseases. In contrast, those that provide interventions (educational, preventive and/or treatment) effectively improve the oral health knowledge, oral hygiene behavior, and oral health status of the children.

Our results reveal that the participation rate of children in Asnani SOHP is good. The majority of the parents graded the program as excellent, very good, and good, which provides a valuable insight that they were very satisfied with the 
program. These results are encouraging as they can also be used as a quality indicator for the implemented program so far. The participation rate of children in Asnani SOHP was high. This may be because Asnani SOHP was the first of Qatar's kind, and many parents instantly provided consent. Children also influenced the parents who were initially reluctant in gaining positive consent when they saw their peers participating in the program and having a good experience with preventive treatment. Similar positive feedback for School Oral Health Programs has been obtained from parents in Australia, United Kingdom, and New Zealand [25-28].

We found that majority of the parents were motivated to continue with treatments advised in Parent Information Sheet, following the dental screening at schools. However, some have indicated facing challenges for continuity of care and suggested strong recommendations for giving priority treatment appointments to school children at private clinics and Health Centers and suggested frequent dental check-ups at school. Similar parental views have resonated in another study also [25].

While in the UK, most parents supported school dental screening, and some relied solely on screening as the source of dental care for their children. The issue of who is responsible for children's health is complex. Some parents consider oral health to be the child's responsibility and the dental profession once a child has reached seven years and beyond [29]. For many interventions delivered in schools, teachers may assume (or be assumed to take) an 'in loco parents position of responsibility. 'Loco parents' is the Latin term for "in the place of a parent." However, a study exploring the views of teachers found they did not wholly accept the moral obligation for the health of their pupils, feeling too much responsibility is placed on schools, and that child health interventions need to be a shared responsibility of the family, school, dental profession, Government, food industry and the community [30,31].

Our results show that parents had noticed a change in the child's behavior towards maintaining their oral hygiene after participating in the Asnani SOHP. Similar studies have also documented that school-based oral health education programs effectively improved oral health knowledge and oral hygiene behaviors among children [32, 35].

Most parents reported that they would follow-up with dental professionals' advice in the "Parent Information Sheet" regarding dental treatment. This is an important finding in our study. It reflects parents' attitude and behavior towards their child's oral health, prioritizing oral health and acknowledging their responsibility. Studies have reported that parents value the concept of dental screening but may not ensure follow-up if the child is not experiencing symptoms [29]. However, it has been determined that parents are ultimately responsible for their children's oral health. Their primary responsibility is to take screened positive children to visit a dentist for further follow-up of oral care [36].

Health promotion strategies that integrate policy development elements, social and environmental determinants may be more effective for oral disease prevention [37]. In terms of policy development, Qatar's State is conceptualizing National School Oral Health Program and National Nutrition guidelines to ensure optimum oral health for all children in Qatar. In terms of the physical environment, the current Asnani SOHP has shown the school's commitment towards children's oral health by providing space and allocating time and operational support for SOHP.

A limitation of this study is that it has evaluated the Asnani SOHP only from the parent's perspective. Further studies on the program's effectiveness and acceptability by children and school administrations need to be evaluated. Job satisfaction of dental professionals in the Asnani school oral health program has recently been evaluated and published [38]. It revealed that the majority of the dental professionals expressed their satisfaction about being a part of the Asnani School Oral Health Program, and 81\% reported a good work-life balance. Secondly, the parent's participation in the online survey was below the anticipated level. This could be attributed to the parents' disinterest with regards to nonacademic matters. Parents' preoccupation in other day-to-day activities and low prioritization of their children's oral health could be the other factors responsible for the survey's suboptimal response.

Similarly, another recent study that examined parents' involvement in school-related activities showed low parental participation due to limited resources and negative views of schools. The study showed that some parents were reluctant to participate in school-related activities because they are insecure about their competence regarding school, program, or activities, lack of formal education, and negative experiences with the education system [39]. These factors also might have resulted in the low participation of parents in this present study.

\section{Conclusion}

Investigation of parental perception of Asnani SOHP shows that it is well accepted by the parents, as reflected by the study results. The program can further be enhanced by conducting regularly supervised toothbrushing in schools and having the children brush their teeth after lunch at schools. This study's parental perspectives articulate the School Oral 
Health Program's acceptability and reflect the common agenda of the shared goal with schools and the dental profession to improve the children's oral health. Driven by the vision of ensuring optimal oral health and preventing dental caries among children, there is strong advocacy for Qatar's National School Oral Health Program. The parental perspectives towards Asnani SOHP expressed in this study are very encouraging and indicate the acceptance of the program, which focusses on dental screening for identification of caries at the earliest stages (whereby it can be reversed), preventive treatments to impede the development of new carious lesions and timely referral for treating the existing carious teeth and preventing their progression.

\section{Compliance with ethical standards}

\section{Acknowledgments}

The authors would like to thank all the parents who participated in the study.

\section{Disclosure of conflict of interest}

The authors declare that there are no conflicts of interest.

\section{Statement of informed consent}

Informed consent was obtained from all individual participants included in the study.

\section{References}

[1] Hygiene-related diseases. Centers for Disease Control and Prevention.

[2] Dental Caries (Tooth Decay) in Children Age 2 to 11. National Institute of Dental and Craniofacial Research.

[3] Bourgeois DM and Llodra JC. Global burden of dental condition among children in nine countries participating in an international oral health promotion programmes, 2012-2013. International Dental Journal. 2014; 64 (2): 2734.

[4] GBD. Disease and Injury Incidence and Prevalence Collaborators. Global, regional, and national incidence, prevalence, and years lived with disability for 354 diseases and injuries for 195 countries and territories, 19902017: a systematic analysis for the Global Burden of Disease Study 2017. Lancet. 2018; 392: 1789-8583.

[5] Seirawan H, Faust S and Mulligan R. The impact of oral health on the academic performance of disadvantaged children. Am J Public Health. 2012; 102(9): 1729-34.

[6] Detty AMR and Oza-Frank R. Oral health status and academic performance among Ohio third-graders, 20092010. J Public Health Dent. 2014; 74(4): 336-42.

[7] Blumenshine SL, Vann WF, Gizlice Z, Lee JY. Children's school performance: impact of general and oral health. J Public Health Dent. 2008; 68(2): 82-7.

[8] Public Health England. Local authorities improving oral health - Commissioning better oral health for children and young people. Public Health England, London. 2014.

[9] Oral Health Promotion: An Essential Element of a Health-Promoting School. WHO Information Series on School Health.

[10] Stein C, Santos NML, Hilgert JB, Hugo FN. Effectiveness of oral health education on oral hygiene and dental caries in schoolchildren: Systematic review and meta-analysis. Community Dent Oral Epidemiol. 2018; 46: 30-37.

[11] Ghaffari M, Rakhshanderou S, Ramezankhani A, Noroozi M, Armoon B. Oral Health Education and Promotion Programmes: Meta-analysis of 17-Year Intervention. Int J Dent Hygiene. 2018; 16: 59-67.

[12] Nery NG, Jordão LMR and Freire MC. School environment and oral health promotion: The National Survey of School Health (PeNSE). Rev Saude Publica 2019; 21: 53-93.

[13] Khoshnevisan MH, Pakkhesal M, Jadidfard MP, Nejadd GG. School-based oral health promotion: a thorough review. Journal Dental School. 2017; 35 (4): 143-149.

[14] Watt R, Fuller, S, Harnett, R, Treasure E, Lowe CS. Oral health promotion evaluation - time for development. Community Dent Oral Epidemiol. 2001; 29: 161-166.

[15] Schou L and Blinkhorn A. Evaluation and planning of oral health promotion programmes. Oral health promotion. Oxford University Press. 1993; 249-270. 
[16] Al-Thani M, Al-Thani A, Al-Emadi A, Al-Chetachi W, Vinodson B, Akram H. Oral Health Status of 12- and 15-YearOld Students in Qatar: Findings from the National Oral Health Survey. Int J Basic Sci Med. 2018; 3(1): 32 - 37.

[17] Benera A, Al Darwish MS, Tewfikd I, Hoffmann GF. The impact of dietary and lifestyle factors on the risk of dental caries among young children in Qatar. J Egypt Public Health Assoc. 2013; 88: 67-73.

[18] Al-Darwish M, El Ansari W and Bener A. Prevalence of dental caries among 12-14-year-old children in Qatar. Saudi Dent J. 2014; 26(3): 115-125.

[19] Al-Darwish MS. Oral health knowledge, behavior and practices among school children in Qatar. Dent Res J (Isfahan). 2016; 13(4): 342-353.

[20] Al-Darwish MS, Abuhassna M and Al-Thomairy SA. Oral Health Knowledge and Sources of Oral Health Information among School Children in Qatar. J Dent Health Oral Disord Ther. 2015; 2(3): 00049.

[21] Marinho VCC, Worthington HV, Walsh T, Clarkson JE. Fluoride varnishes for preventing dental caries in children and adolescents. Cochrane Database of Systematic Reviews. 2013; 7: CD002279.

[22] Saloranta AA, Forss H, Walsh T, Hiiri A, Nordblad A, Mäkelä M, Worthington HV. Sealants for preventing dental decay in the permanent teeth Cochrane Database of Systematic Reviews. 2013; 3: CD001830.

[23] Department of Education. The education act. London: HMSO. 1918.

[24] Baltutis LMD, Morgan MV. Parental Perceptions of a School Dental Service in Australia. Community Dent Health. 2002; 19(4): 251-7.

[25] Yusuf KH and Wright CR. Evaluation of a pilot oral health promotion programme 'Keep Smiling': perspectives from GDPs, health champions and school staff. Br Dent J. 2015; 218(8): 455-9.

[26] Evans P, Pearson N and Simons D. A school-based oral health intervention in East London: The Happy Teeth fluoride varnish programme. Br Dent J. 2013; 215(8): E14.

[27] Drummond BK, Gaffney M and Marshall K. An Investigation of the Views of Parents in Otago on Dental Care for Primary School-Aged Children by the Community Oral Health Service Prior to the Introduction of the Hub-Based Clinic System. N Z Dent J. 2016; 112(4): 108-115.

[28] Preston ST, Davies GM and Craven R. An investigation of parents' attitudes to dental health and school dental screening. Community Dent Health. 2001; 18: 105- 109.

[29] Goldthorpe J, Epton T, Keyworth C, Calam R, Armitage C. Who is responsible for keeping children healthy? A qualitative exploration of the views of children aged 8-10 years old. BMJ Open. 2019; 9(5): e025245. Published online. 27 May 2019.

[30] Todd C, Christian D, Davies H, Rance J, Stratton G, Rapport F, Brophy S. Head teachers' prior beliefs on child health and their engagement in school-based health interventions: a qualitative study. BMC Res Notes. $2015 ; 8: 161$.

[31] Blake H, Dawett B, Leighton P, Rose-Brady L, Deery C. School based educational intervention to improve children's oral health-related knowledge. Health Promot Pract. 2015; 16: 571-82.

[32] Jaime RA, Carvalho TS, Bonini GC, Imparato J, Mendes FM. Oral health education program on dental caries incidence for school children. J Clin Pediatr Dent. 2015; 39: 277-83.

[33] Esan A, Folayan MO, Egbetade GO, Oyedele TA. Effect of a school-based oral health education programme on use of recommended oral self-care for reducing the risk of caries by children in Nigeria. Int J Paediatr Dent. 2015; 25: 282-90.

[34] Moallemi ZS, Murtomaa H and Virtanen JI. Change in conceptions of Iranian pre-adolescents' oral health after a school-based programme: challenge for boys. Oral Health Prev Dent. 2014; 12: 21-8.

[35] Tickle M, Milsom KM, Buchanan K, Blinkhorn AS. Dental screening in schools: the views of parents, teachers and school nurses. Br Dent J. 2006; 201: 769-773.

[36] Edasseri A, Barnett TA, Kâ K, Henderson M, Nicolau B. Oral health promoting school environments and dental caries in Québec children. Am J Prev Med. 2017; 53: 697-704.

[37] AlYafei NA, Jaleel BNF. Job satisfaction of dental professionals in Asnani School Oral Health Program. International Journal of Dental Sciences. 2020; 2(2): 10-14.

[38] Helgøy I, Homme A. Increasing parental participation at school level: a "citizen to serve" or a "customer to steer"? Nordic Journal of Studies in Educational Policy. 2017; 3(2): 144-154. 